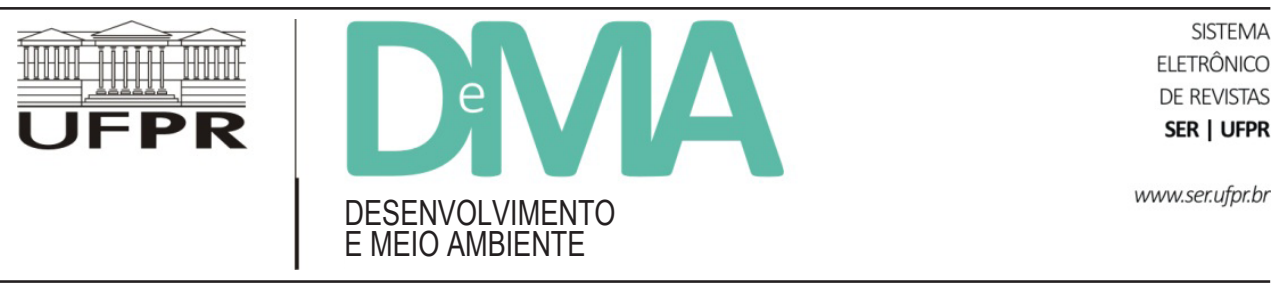

\title{
Pensamento socioambiental e a economia ecológica: nova perspectiva para pensar a sociedade
}

\section{Pensamiento socioambiental y economía ecológica: nueva perspectiva para pensar la sociedad}

\section{Socio-Environmental Thinking and Ecological Economics: a New Perspective to Think About Society}

\author{
Clóvis CAVALCANTI ${ }^{1 *}$ \\ ${ }^{1}$ Fundação Joaquim Nabuco, Universidade Federal de Pernambuco (UFPE), Recife, PE, Brasil. \\ *E-mail de contato: cloviscavalcanti.tao@gmail.com
}

Artigo recebido em 16 de outubro de 2015, versão final aceita em 25 de novembro de 2015.

RESUMO: Diante do que considera uma estreiteza disciplinar das ciências ligadas à sociedade e à natureza, que impedem visão de conjunto da problemática ecológico-econômica, a Economia Ecológica surge sem dependência, seja da economia, seja da ecologia, resultando de integração entre elas. A universidade possui disciplinas(unidimensionais); o mundo real tem problemas concretos (multidimensionais; caso dos socioambientais). Fronteiras disciplinares são construtos acadêmicos arbitrários. O aparecimento da Economia Ecológica se direciona para o tratamento desse embate. A conclusão não pode ser outra: a Economia Ecológica não constitui um ramo da economia (nem da ecologia). A enormidade do impacto devastador da escala humana no resto da criação resulta do fato de que, crescer significa usar o meio ambiente: envolve "custos de oportunidade" ambientais. Entretanto, a visão dominante da economia ("economia convencional", ou visão econômica da economia) ignora completamente a dimensão dos recursos da natureza em seu modelo. Quando muito, o que faz é imaginar o meio ambiente como apêndice da economia-atividade (economia ambiental, ou visão econômica do meio ambiente). Para a Economia Ecológica, a questão é conceber a economia-atividade como sistema aberto dentro do ecossistema. Nessa ótica, não se entende que haja criação de riqueza. Há, sim, transformação (metabolismo) de matéria e energia de baixa entropia em matéria e energia de alta entropia como estabelecem as incontornáveis leis da termodinâmica. Essa perspectiva significa a visão ecológica da economia. Ou seja, corresponde a dizer que existirá uma escala máxima sustentável do sistema econômico com respeito ao ecossistema. A questão, pois, é encontrar a escala ótima do macrossistema econômico, o qual não passa de um subsistema aberto do ecossistema global (termodinamicamente fechado). A economia não pode ultrapassar limites ditados pela natureza, sobretudo quanto à observância de limitações decorrentes das leis da termodinâmica. Na visão da Economia Ecológica, a natureza é condição de suporte insubstituível, único, de 
tudo o que a sociedade pode fazer. Tal posição equivale a rejeitar paradigmas vigentes que levam a verdadeiro culto do crescimento econômico.

Palavras-chave: economia tradicional; economia ambiental; economia ecológica; termodinâmica; entropia; limites ecológicos; crescimento econômico.

RESUMEN: Frente a lo que considera una restricción disciplinar de las ciencias de la sociedad y de la naturaleza que impiden una visión integrada de la problemática ecológico-económica, la Economía Ecológica aparece sin dependencia, sea de la economía, sea de la ecología y resulta de la integración de ambas. La universidad posee disciplinas (unidimensionales); el mundo real tiene problemas concretos (multidimensionales como los socioambientales). Fronteras disciplinarias son constructos académicos arbitrarios. El aparecimiento de la Economía Ecológica se dirige hacia el tratamiento de este enfrentamiento. La conclusión no puede ser otra: la Economía Ecológica no constituye una rama de la economía (ni de la ecología). La inmensidad del impacto abrumador de la escala humana sobre las demás creaciones resulta de que crecer significa utilizar el medio ambiente: involucra "costos de oportunidad" ambientales. Sin embargo, la visión dominante de la economía ("economía convencional", o visión económica de la economía) ignora de vez la dimensión de los recursos de la naturaleza en su modelo. Cuando demasiado, lo que hace es imaginar el medio ambiente como un apéndice de la economía-actividad (economía ambiental, o visión económica del medio ambiente). Para la Economía Ecológica, la cuestión es concebir la economía-actividad como sistema abierto en el ecosistema. Bajo esta óptica, no se entiende que exista creación de riqueza. Existe sí transformación (metabolismo) de materia y energía de baja entropía en materia y energía de alta entropía - como establecen las inevitables leyes de la termodinámica. Esta perspectiva significa la visión ecológica de la economía. Es decir, corresponde a que existirá una escala máxima sustentable del sistema económico respecto al ecosistema. Se trata pues de encontrar la escala óptima del macro sistema económico, que no es más que un subsistema abierto del ecosistema global (termodinámicamente cerrado). La economía no puede rebasar límites dictados por la naturaleza, especialmente en lo que atañen las limitaciones debido a las leyes de la termodinámica. En la visión de la Economía Ecológica, la naturaleza es condición de soporte insustituible, único, de todo lo que la sociedad puede hacer. Tal posición equivale a rechazar paradigmas vigentes que resultan de una adoración al crecimiento económico.

Palabras clave: economía tradicional; economía ambiental; economía ecológica; termodinámica; entropía; límites ecológicos; crecimiento económico.

ABSTRACT: Ecological Economics represents an attempt to overcome the disciplinary narrowness of the traditional sciences dealing with society, the economy and nature. It adopts a transdisciplinary approach with an integrating view of ecological-economic problems, rejecting any dependence either on economics or ecology. The university possesses (unidimensional) disciplines; the real world has concrete (multidimensional) problems, as in the case of the socio-environmental ones. Disciplinary frontiers are arbitrary academic constructs. Ecological Economics directs its attention to that conflict. The conclusion cannot be otherwise: Ecological Economics does not constitute a branch of economics (nor is it of ecology). The enormity of the devastating impact of the human scale on the rest of the creation results from the fact that to grow means to use the environment: it involves environmental "opportunity costs". However, the dominant view of economics ("conventional economics", or the economic view of the economy) ignores completely the dimension of the resources of nature in its model. The most it does is to imagine the environment as an appendix of economic activity (as environmental economics, or the economic view of the environment, offers us). To Ecological Economics what matters is to imagine the economy as an open subsystem inside the ecosystem. In this perspective, the idea of wealth creation does not exist. What happens is a transformation (metabolism) of low-entropy into high-entropy matter and energy - as the inexorable laws of thermodynamics determine. This perspective represents the ecological view of the economy. In other words, it corresponds to the notion that there will be a maximum sustainable scale of the economic system in relation to nature. The question thus consists in finding the optimum scale of the economic macrosystem, which is nothing more than an open subsystem of the global, thermodynamically 
closed ecosystem. Nature limits cannot be surpassed by the economy, chiefly in terms of the observance of limitations resulting from the laws of thermodynamics. In the view of Ecological Economics, nature is the irreplaceable, single basic support of anything society can do. Such position corresponds to the rejection of the ruling paradigms that lead to a true worship of economic growth.

Keywords: traditional economics; environmental economics; ecological economics; thermodynamics; entropy; ecological limits; economic growth.

\section{Visão da problemática econômico-ecológica}

A crescente percepção de que o sistema ecológico de sustentação da vida encontra-se cada vez mais ameaçado constitui o ponto de partida da reflexão que deu origem à Economia Ecológica (EE). Foi esse, com efeito, um consenso do workshop realizado no Aspen Institute (Wye Island, Maryland, USA), em 24-26.5.1990, do qual resultou a proposta de uma nova abordagem da sustentabilidade $^{1}$. Nesse contexto, a EE deveria diferir tanto da economia como da ecologia convencionais, em termos da envergadura dos problemas de que deveria cuidar. Do mesmo modo, deveria penetrar a fundo na compreensão das interações meio ambiente-economia. Não pode haver dúvida, assim, de que a EE vê a economia humana como parte - subsistema - do todo maior, que é a natureza. Não se trata de aceitar um dogma de fé, mas de reconhecer inquestionável evidência: não existe sociedade (e economia) sem sistema ecológico, mas pode haver meio ambiente sem sociedade (e economia). Enquanto isso, a economia (ciência econômica) convencional trata apenas da espécie humana, esquecendo todas as outras, e a ecologia convencional enxerga todas as espécies, menos a humana.

Ao constatar, em ambos os casos, a necessidade de se superar a estreiteza disciplinar que impede uma visão de conjunto da problemática ecológico-econômica, a EE surge sem dependência disciplinar, seja da economia, seja da ecologia, resultando, ao revés, de uma integração entre elas. Sua visão de mundo teria que ser transdisciplinar, com foco nas relações entre ecossistemas e sistemas econômicos no sentido mais amplo possível. Como dizem Costanza, Daly e Bartholomew (in: Costanza, 1991), "[b]y transdisciplinary we mean that ecological economics goes beyond our normal conceptions of scientific disciplines and tries to integrate and synthesize many different disciplinary perspectives". Cabe aqui a observação de que nenhuma disciplina possui precedência intelectual sobre qualquer outra em matéria de realização da sustentabilidade. Isso se aplica à física, à biologia, à ecologia - e à economia. Por outro lado, a segmentação das disciplinas é uma convenção acadêmica, enquanto os problemas que interessam não se localizam no âmbito da disciplina A ou B.

A universidade tem disciplinas (unidimensionais); o mundo real tem problemas concretos (multidimensionais; caso dos socioambientais). Fronteiras disciplinares são construtos acadêmicos arbitrários. $\mathrm{O}$ aparecimento da EE se direciona para o tratamento desse embate. A conclusão não pode ser outra: $a$ EE não constitui um ramo da economia (nem da ecologia, é claro). Tanto poderia se chamar economia ecológica como ecoeconomia, ou ainda ecologia econômica. José Eli da Veiga tem proposto que se fale de uma perspectiva socioambiental; Martínez Alier, de ecologia humana. $\mathrm{O}$ fato de se haver adotado o termo "economia ecológica", que pode facilmente levar a confusão com a noção de economia ambiental, é motivo de não poucos equívocos.

Como pós-economista ou economista dissidente, indagado sobre qual seja a principal tarefa da economia, sinto-me inclinado a seguir a corrente que dá ênfase ao papel da economia de explicar comportamento humano condicionado pela escassez. A vida é uma sucessão contínua de escolhas que representam o confronto de diferentes valorações. Isto ocorre porque, de algum

\footnotetext{
1 Participaram do encontro 38 pessoas, entre as quais Charles Perrings, Colin Clark (matemático), Cutler Cleveland, Enzo Tiezzi, Garrett Hardin, Herman Daly, Joan Martínez Alier, Kenneth Boulding, Richard Norgaard, Robert Costanza, Silvio Funtowicz, Talbott Page, Tomasz Zylicz. Fui um dos participantes (por descuido dos organizadores, suponho).
} 
modo, os recursos - inclusive e, sobretudo, o tempo são escassos. Portanto, a realização dos fins humanos é restringida pela escassez dos meios. Se um fim é preferido, isto envolve o sacrifício de outros. Não é por outra razão que uma das mais bem conhecidas definições da economia sublinha o fato de que a economia "é a ciência que estuda o comportamento humano como uma relação entre fins e meios escassos que têm usos alternativos" (Robbins, 1984, p. 16). Nas palavras de Alfred Marshall (1961, p. xv), por outro lado, a economia ou teoria econômica diz respeito principalmente a seres humanos que são impelidos para a mudança e o progresso. Sua definição de economia, que ele iguala à economia política, consiste em dizer que ela se dedica ao exame "daquela parte da ação individual ou social que está mais estreitamente conectada com o alcance e o uso dos requisitos materiais do bem-estar" (Marshall, 1961, p. 1). Esta é uma interpretação que se enquadra dentro dos moldes da economia como uma disciplina que trata de escolhas, como na análise do comportamento do consumidor sob condições de desejos ilimitados e recursos finitos. Implícita nessa visão encontra-se a ideia de que se comportar de maneira econômica significa tornar a atividade de uma pessoa ou de uma organização "eficiente", ao invés de esbanjadora (Knight, 1965, p. 510). Significa escolher o menos custoso curso de ação ou aquele que maximiza os benefícios líquidos da ação.

Carlos Gabaglia Penna, falecido professor da Engenharia Ambiental da PUC-Rio ${ }^{2}$, explica que, no mundo natural, o crescimento nunca é linear, e sim exponencial. E cita um exemplo clássico da realidade desse fenômeno:

imaginemos que um lago contenha uma espécie de alga que, ao cobrir toda a superfície do corpo d'água, sufocará a vida nele existente. A comunidade de algas dobra de tamanho a cada dia. Suponhamos que, em 30 dias, as algas tomarão o lago todo. No $21^{\circ}$ dia, as algas cobrem tão somente $0,2 \%$ da superfície (menos de $0,0001 \%$ no $10^{\circ}$ dia). Em apenas mais oito dias, já terão coberto a metade e, no dia seguinte, o lago estará completamente tomado pelas algas, eliminando o oxigênio disponível da água (Gabaglia Penna, 2008).
Em outras palavras, crescimento geométrico leva sempre, na natureza, ao desastre (caso da bola de neve, do crescimento celular ilimitado, etc.). Por que teria que ser diferente no tocante ao sistema econômico, se ele, como postula a EE, é um subsistema da natureza? Para o subsistema valem as mesmas leis que governam o todo. Esse é um princípio da EE aceito sem controvérsias.

Segundo Gabaglia Penna, a física, a teoria dos sistemas (ou teoria do caos) e a termodinâmica, mais especificamente a Segunda Lei, dão suporte a essa argumentação. A expansão econômica significa normalmente maior transformação de matéria e energia - o que, pelas leis da física, eleva a temperatura do sistema. Um sistema (ou subsistema) de temperatura elevada tem uma entropia maior do que a de um com baixa temperatura. "As crescentes conversões de materiais e energia em bens e serviços da sociedade de consumo estão inequivocamente aumentando a entropia do planeta. Ou seja, aumentando a desordem do sistema Terra, representada pela degradação do ambiente natural. Esta lei é tão imutável quanto a Lei da Gravidade" (Gabaglia Penna, 2008).

Deve ser óbvia, para todos nós, economistas tradicionais ou não, a enormidade do impacto devastador da escala humana no resto da criação. Trata-se, como salientam Daly \& Farley (2004), de algo novo debaixo do sol. Contribui para tanto um quadro de caráter social e cultural em que grande parte do aumento do consumo material é impulsionada pela propaganda - muitas vezes, da mais absurda futilidade. Isso não quer dizer que o crescimento seja necessariamente mau. Haverá crescimento indispensável - como no caso da produção para a satisfação das necessidades básicas, especialmente dos pobres. De qualquer forma, crescer é usar o meio ambiente, inevitavelmente. Vale aqui lembrar o que diz Alfred North Whitehead (1861-1947), em seu livro $A$ função da razão (1985). Em suas palavras: “As formas mais elevadas de vida estão ativamente empenhadas em modificar o seu meio ambiente. No caso da espécie humana, esse ataque efetivo ao meio ambiente é o fato mais notável de sua existência". Tal ataque se desdobra em três etapas: (i) viver (garantir nossa sobrevivência - "obrigação" de todo organismo vivo), (ii) viver bem

\footnotetext{
2 No site http://arruda.rits.org.br/oeco/servlet/newstorm.ns.presentation.NavigationServlet?publicationCode $=6 \&$ pageCode $=90 \&$ textCode $=27115$. Acesso em: 23 abr. 2008).
} 
(dispor do melhor ambiente possível; ninguém sobrevive no próprio lixo) e (iii) viver melhor (conquistar novos patamares de qualidade de vida; aprimorar-se; progredir, prosperar). Conclusão de Whitehead: "A função primordial da razão é direcionar o ataque ao meio ambiente". E ainda: "A função da razão é promover a arte da vida". Ou seja, atacar o meio ambiente, sim, mas de forma inteligente e com o propósito de se viver melhor - buscar a felicidade, no fim de contas. Penso que pouca gente possa discordar disso, mas, notando como as pessoas se viciaram hoje em shopping centers, talvez esteja errado em minha percepção.

\section{Meio ambiente e o processo econômico}

Não deveria haver dúvida de que considerar o processo econômico no marco do meio ambiente é uma necessidade imperiosa, talvez mesmo uma banalidade. Contudo, a visão dominante da economia ("economia convencional", digamos, ou visão econômica da economia) não funciona assim. O que se considera é uma situação como a da Figura 1, na qual a natureza é uma externalidade. Nesse enfoque, o sistema econômico não encontra limites onde esbarrar. Ele pode tudo. Sua expansão não envolve custos de oportunidade.

\section{Fluxos Monetários}

(modelo convencional do sistema econômico)

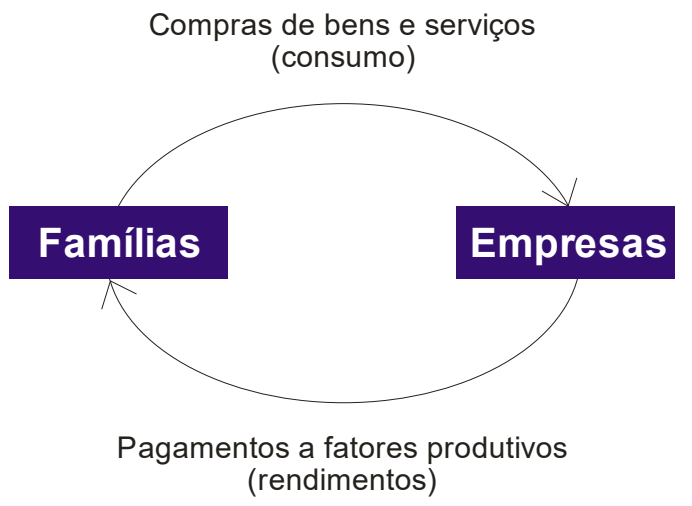

FIGURA 1 - A economia-atividade como sistema isolado (visão econômica da economia).
Quando muito, o que a economia convencional faz é imaginar o meio ambiente como apêndice da economia-atividade, a qual é vista como o todo; neste caso, o ecossistema aparece como berloque, almoxarifado, dispensa (Figura 2). Trata-se de uma tentativa de internalizar as externalidades. É aqui que surge o campo conhecido como economia ambiental: visão econômica da ecologia.

\section{Economia $\longleftarrow$ Meio Ambiente}

FIGURA 2 - O meio ambiente como apêndice da economia-atividade (visão econômica da ecologia).

Já para a EE, a questão é conceber a economia-atividade como sistema aberto dentro do ecossistema (o ecossistema é o todo; a economia, uma parte. Ver Figura 3). Matéria e energia entram no sistema, passam pelo processo metabólico do throughput (transumo) e viram lixo. Nesse modelo não há criação de riqueza. Há transformação (metabolismo) de matéria e energia de baixa entropia em matéria e energia de alta entropia - como estabelecem as incontornáveis leis da termodinâmica. À perspectiva da EE pode-se atribuir a característica de visão ecológica da economia. Segundo ela, o sistema econômico tem aparelho digestivo e circulatório (somente o segundo é imaginado no modelo da economia convencional, como se o trato digestivo de um organismo pudesse ser ignorado!).

\section{Modelo Biofísico do Sistema Econômico} (fluxos de matéria e energia)

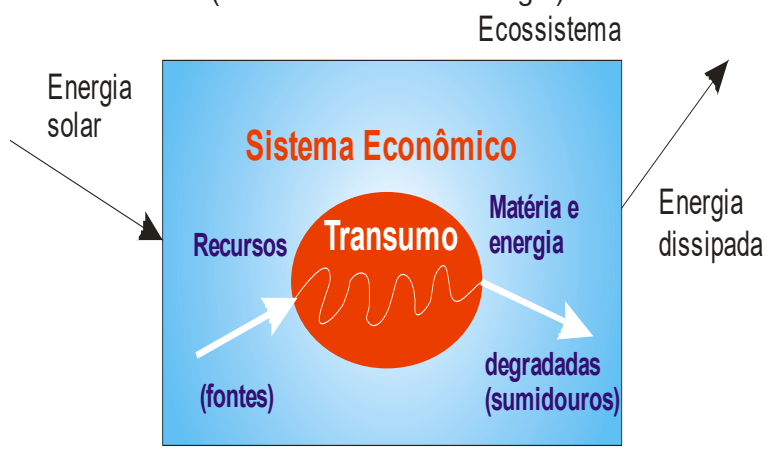

FIGURA 3 - A economia-atividade como sistema aberto dentro do ecossistema (visão ecológica da economia). 
Uma implicação óbvia da perspectiva econômico-ecológica é que o sistema econômico, ao se expandir, incorre em custos de oportunidade ambientais positivos (o meio ambiente é escasso). Se esses custos já foram tão ínfimos que se podia ignorá-los, o fato é que mais economia implica menos meio ambiente. Seria bom que não fosse assim. É aqui que se chega à conclusão de que a visão de mundo prevalecente, que dá ênfase inusitada ao crescimento econômico como solução para tudo, como prioridade absoluta em relação a outros objetivos (a valorização do ter; o PAC dos governos Lula e Dilma), termina podendo ser classificada como fé, fetiche, mania, dogma. Sem dúvida, ao mesmo tempo, forma-se uma confusão entre crescimento (aumento) e desenvolvimento (evolução, transformação, "promoção da arte da vida").

A visão econômica da economia preceitua que não há custos ambientais de oportunidade para o processo econômico, que esse é um falso dilema. Ao mesmo tempo, alguns economistas chegam a dizer, como no exemplo dado por J. R. McNeill (2000), que "o mundo, com efeito, pode continuar seu negócio sem recursos naturais". Na microeconomia, como se sabe, prevalece o cálculo (conceito) do ótimo (eficiência máxima da alocação de recursos escassos). Trata-se da regra de quando é para parar a expansão da escala (da firma). Enquanto isso, na macroeconomia prevalece a busca do crescimento ilimitado. Ignora-se nela o ótimo do crescimento (ou quando o crescimento deveria parar). A perspectiva da EE é de que existirá uma escala máxima sustentável do sistema econômico com respeito ao ecossistema, escala essa a ser determinada pela comparação de benefícios econômicos marginais com custos ambientais marginais - como se faz no caso do equilíbrio da firma. Ao se acionar a economia, de fato, não se pode ignorar que a depreciação dos ativos naturais (capital natural) é real: custos de oportunidade. Aumentar a produção econômica implica sacrifício de recursos, tais como florestas, solo, água, ar, biodiversidade, estabilidade climática, etc. Notar isso é decorrência da visão ecológica da economia. Em síntese, trata-se de encontrar a escala ótima do macrossistema econômico, permitindo a separação entre (i) crescimento genuinamente econômico (quando os benefícios marginais do aumento da economia superam os custos marginais socioambientais do processo) e (ii) crescimento antieconômico (quando, pelo contrário, os benefícios marginais do aumento da economia se tornam inferiores aos custos marginais). Supõe-se, é claro, que, em algum momento, benefícios e custos marginais se igualem.

Tudo isso, no fundo, é a essência do que concebe a economia ecológica. Sua cosmovisão internaliza o sistema econômico na natureza. Ou, como diz um expoente da economia convencional (The Economist, coluna "Face Value", 4.7.2009): "you cannot negotiate with nature". Mas negociar com a natureza é o que se imagina poder conseguir dentro dos paradigmas vigentes. A explicação para demonstrar que isso é inviável se deve a Nicholas Georgescu-Roegen (G-R, abreviadamente), em especial no seu consagrado, mas pouco lido (lamentavelmente), The Entropy Law and the Economic Process (de 1971). A demonstração de G-R parte do enunciado de que a economia não passa de um subsistema aberto do ecossistema global (o qual é termodinamicamente fechado), submetida, aquela, pois, a limites ditados pela natureza. G-R explica ainda, de forma rigorosa, que o que os economistas convencionais concebem é a economia como um sistema isolado, autocontido e a-histórico - configurado por um fluxo circular entre produção e consumo, sem entradas e sem saídas no sistema, conforme se expõe em qualquer livro-texto com o gráfico do "fluxo circular da riqueza" (Figura 1). A ciência da economia não oferece absolutamente qualquer sinal de reconhecimento do papel dos recursos naturais no processo econômico, sublinha G-R (1971, p. 19), que conclui:

\begin{abstract}
Se a economia considerasse a natureza entrópica do processo econômico, poderia ter sido capaz de alertar seus companheiros de trabalhado no aprimoramento da humanidade - as ciências tecnológicas - de que "maiores e melhores" máquinas de lavar, automóveis e superjatos conduzem necessariamente a "maior e melhor" poluição.
\end{abstract}

A forte crítica de G-R é acentuada ao mostrar que o modelo convencional ignora as Leis da Termodinâmica, as quais definem todos os processos de transformação energética do universo. É aqui que G-R ressalta que, em essência, e do ponto de vista material, o processo econômico consiste na transformação de matéria e energia de baixa entropia em matéria e energia de alta entropia, ou seja, transformação de riqueza em waste (lixo) - e 
não o inverso, como se admite (é comum, por exemplo, ouvir os noticiários de TV indicar que o PIB é "a soma das riquezas produzidas"). Resulta daí que, quanto mais rápido for o processo econômico, tanto mais depressa sujeira se acumulará. No entanto, ressalva o pai da EE para Martínez Alier (1995, p. 27), o principal expoente da crítica ecológica da economia -, seria extremamente absurdo pensar que o processo econômico só exista para produzir lixo. Sua ressalva, irrefutável - julga -, "é de que o produto verdadeiro desse processo é um fluxo imaterial, de gozo da vida" (Georgescu-Roegen, 1971, p. 282). Sem introduzir em nosso "armamentarium" (expressão sua) o conceito de enjoyment of life, que não possui dimensão física e, portanto, pode crescer sem limites, no entender de G-R, não estaríamos no mundo econômico. É o gozo da vida ou a alegria de viver que representa a diferença entre o processo econômico "e a marcha entrópica do ambiente material" (Georgescu-Roegen, 1971, p. 282), explicada pela termodinâmica. Assim, G-R propõe a hipótese de que tudo o que sustenta o life enjoyment, direta ou indiretamente, pertence à categoria de valor econômico.

Enquanto isso, o mundo necessita de que se encontre um modelo de economia que seja durável, compatível com as limitações que a natureza impõe, obediente às Leis da Termodinâmica. Daí, o aparecimento da noção do desenvolvimento sustentável, por mais discutível que seja. Sobre isso, a propósito, fui procurado em 2006 por uma estudante do Rio Grande do Norte que quis saber: "Como o senhor entende o desenvolvimento sustentável?" Respondi: "Na verdade, só pode haver desenvolvimento que seja sustentável. Pois se ele é insustentável, vai acabar. Não é, portanto, desenvolvimento, mas alguma coisa como um espasmo, passageira. O desenvolvimento sustentável é aquele que permanece. Quem o sustenta em primeiro lugar é a natureza, o ecossistema, do qual dependemos para tudo. Dessa forma, para que possa sustentar-se, ele tem que levar em conta as regras e os limites que lhe são determinados. Sem descuidar do bem-estar humano, dos valores da cultura, da realização plena da cidadania". A aluna quis saber ainda como se entende a sustentabilidade do ponto de vista socioambiental. Expliquei: "O desenvolvimento, para ser sustentável, deve usar os recursos renováveis a um ritmo inferior ao da sua reprodução; e os não renováveis, procurando investir os rendimentos deles obtidos para o desenvolvimento científico e tecnológico no sentido de encontrar substitutos renováveis. No fundo, trata-se de minimizar o uso da natureza, com obtenção de máximo bem-estar social".

Fui ainda questionado: "Como sabemos, na eterna busca por crescimento econômico, o homem esqueceu do equilíbrio necessário à sociedade para crescer de modo sustentável. Será que um dia teremos uma sociedade com essa configuração? Quais as experiências que poderíamos apontar nesta direção?" Esclareci: "Nunca existiu uma 'eterna busca por crescimento econômico'. De fato, a civilização tem 5.000 anos e o crescimento só começou a acontecer nos últimos 250 anos. Hoje se pensa e age como se o crescimento econômico fosse a regra para a Humanidade. Não é. Crescimento é aumento, expansão da economia. Significa necessariamente esgotamento de alguns recursos, destruição de alguma coisa do meio ambiente, pois a Natureza é quem fornece os meios biofísicos para a economia expandir-se. Não existe nenhum exemplo de sociedade desenvolvida que seja ecologicamente sustentável, simplesmente porque as sociedades desenvolvidas (Grã-Bretanha, Estados Unidos, Alemanha, etc.) chegaram a esse nível há menos de 250 anos. Sustentáveis foram as sociedades indígenas no Brasil, que tinham 12.000 anos de existência quando os portugueses chegaram aqui". Quem garante que a sociedade americana vai ser como é daqui a mais 250 anos? Ninguém garante, nem mesmo daqui a vinte anos! E daqui a 12.000?

Caberia então a pergunta de se é possível equilibrar crescimento econômico ilimitado ("espetáculo do crescimento") com um meio ambiente saudável. A perspectiva do ecossistema é de não ser possível. Crescimento implica sempre menos meio ambiente. De fato, o planeta não cresce; se a economia cresce - e ela é parte do planeta -, obviamente menos meio ambiente restará. Quanto mais gente na Terra, quanto mais produção econômica, tanto menos natureza. Em outras palavras, no jargão dos economistas, existe aí um "custo de oportunidade ambiental”. O que pode, sim, acontecer é um desenvolvimento ambientalmente sustentável. A questão é que desenvolvimento (que significa mudança, evolução, progresso) não é crescimento (aumento, expansão). Amartya Sen (1999, p. 3) conceitua o desenvolvimento 
como um processo de expansão das liberdades reais, algo de que as pessoas gostam, ou seja, mais cidadania. Isso não é crescimento, embora possa incluí-lo - como ao se aumentar a produção de bens para as pessoas que deles carecem. Sen é Prêmio Nobel de Economia de 1998: sabe do que está tratando. Daí, não fazer sentido falar em crescer sustentavelmente. Desenvolver sustentavelmente, porém, é possível. E isso é o que acontece com o ser humano (e todos os organismos vivos): crescem; param de crescer; e nunca deixam de desenvolver-se - até o fim inevitável. Não se deveria ter confusão a esse respeito.

\section{Pensamento econômico-ecológico: algumas referências}

Resumindo (Cavalcanti, 2010): a economia convencional exclui a natureza como externalidade do processo econômico; a economia ambiental se preocupa em internalizar e dar preço à natureza, com a tendência de vê-la como amenidade (uma ideia implícita na noção vulgar do "verde"); e a economia ecológica atribui à natureza a condição de suporte insubstituível, único, de tudo o que a sociedade pode fazer. A visão econômica tradicional inclui não só o pensamento da economia neoclássica de F. von Hayek (1899-1992), Milton Friedman (1912-2006), Robert Solow (1924-) e seus seguidores (no Brasil, nome ilustre é o de Mário Henrique Simonsen, 1935-1997), como também o dos keynesianos, marxistas, institucionalistas, estruturalistas, monetaristas, economistas políticos: um verdadeiro pensamento único. Entre os brasileiros não neoclássicos, Celso Furtado (1920-2004) sobressai por se afastar desse molde de pensamento único, tentando dar ênfase, em alguns momentos, a fatores ambientais no desenvolvimento econômico (ver, Furtado, 1974, v.g.). André Lara Rezende, um dos pais do Plano Real (de 1994), ingressou no campo da crítica ecológica da economia em época recente, de que é prova seu Os limites do possível (2013). Um economista próximo da visão ecológica talvez seja Eduardo Giannetti da Fonseca, mais filósofo que propriamente um profissional da ciência econômica, contudo. Preocupações ambientais não se projetam, como de praxe, entre nomes importantes da economia standard, a exemplo de Luiz Carlos Bresser Pereira, Maria da
Conceição Tavares, Edmar Bacha ou Delfim Netto. No entanto, surgem economistas ambientais importantes no quadro brasileiro, como: Ronaldo Serôa da Motta, Cecília Lustosa, Maurício Tolmasquin, Carlos Eduardo (Cadu) Young, Antônio Evaldo Comune.

Quanto à economia ecológica, identificar quem a pratique requer que se defina o leque de tendências que se manifestam quanto a perspectivas de entendimento dessa área de investigação. Na verdade, a EE não se define como uma ciência. O que brotou na reunião de Wye Island em junho de 1990 foi a sugestão de considerá-la como "campo emergente transdisciplinar de estudo" (Costanza et al., 1991, p. 3) com a pretensão de cobrir espaços não abarcados pelas disciplinas científicas existentes. Seria uma "orquestração de ciências" (Martínez Alier, 2007, p. 67), comportando diversidade de pensamento entre economistas ecológicos mesmo. Martínez Alier (2007, p. 21) distingue três correntes principais do ambientalismo, com vários elementos comuns que as caracterizariam, todas elas, porém, desqualificadas, ignoradas ou depreciadas pelos antiecologistas (aqueles que veem o meio ambiente como uma "barreira ao desenvolvimento"). Uma corrente ambientalista da classificação de Martínez Alier é a do "culto ao silvestre", do valor sagrado da natureza, da ecologia profunda, da atitude biocêntrica. Outra corrente se poderia chamar de "evangelho da ecoeficiência": um ecologismo de resultados que se preocuparia com os efeitos do crescimento econômico. Caso da economia verde. Finalmente, a terceira corrente é a do "ecologismo dos pobres", caracterizada pelo interesse material nos "recursos e serviços ambientais proporcionados pelo meio natural para a subsistência humana" (Martínez Alier, 2007, p. 335).

A argumentação do ecologismo dos pobres propõe que a luta entre economia e ecologia não pode ser resolvida pela internalização das externalidades, nem pela modernização ecológica ou pela ecoeficiência. Ela levanta a discussão quanto à "incidência desigual dos danos ambientais ante não só as demais espécies ou as futuras gerações de humanos, mas em nossa própria época" (Martínez Alier, 2007, p. 89). Central para o ecologismo dos pobres é o tema da incomensurabilidade dos valores. Nesse particular, a tarefa da EE seria estudar diferentes processos de tomada de decisão num contexto de "comparabilidade fraca de valores", além de conflitos 
distributivos e "incertezas sem solução" (Martínez Alier, 2007, p. 55). Nas valorações monetárias, a relevância de um serviço da natureza para o mercado é o fator que conta. Entretanto, serviços da natureza possuem múltiplos significados. Um mangue, por exemplo, além de seu papel econômico, importa do ponto de vista da biodiversidade, da paisagem, da sobrevivência de populações vizinhas, da proteção contra inundações, da cultura, do sagrado. Daí, resultarão diferentes valores para esse ecossistema que demandam uma visão integrada das suas dimensões física, social, cultural e espiritual. É como sublinha Martínez Alier (2007, p. 355): "Quando as pessoas de cor eram obrigadas a viajar sentando-se na última fileira de bancos dos veículos nos Estados Unidos, isso não podia ser compensado na escala da dignidade humana, com uma passagem mais barata".

O maior nome da EE no mundo hoje é o de Herman Daly, que tende a combinar elementos das três correntes do ecologismo. Ele foi aluno de Georgescu-Roegen e tem elaborado a visão termodinâmica do processo econômico em novas direções. Segue em seu raciocínio os princípios biofísicos de seu mestre. Outro nome de peso é o de Martínez Alier, que foi presidente da ISEE (em 2005-2007), devendo ser enquadrado no ecologismo dos pobres (ele tem se dedicado ao estudo de movimentos populares ambientalistas, como o Chipko, na Índia, e o das reservas extrativistas de Chico Mendes). Robert Goodland (1939-2013), ecólogo, chamado em certa época de "a consciência do Banco Mundial", estava perto do culto ao silvestre. O pai do conceito da pegada ecológica, William Rees, e seu antigo aluno e elaborador do conceito, Mathis Wackernagel, fazem parte da lista dos economistas ecológicos de destaque, assim como Peter Victor e Tim Jackson.

Um seguidor de Georgescu e do ecologismo dos pobres, também ligado à questão da justiça ambiental, é o mexicano David Barkin. Na Argentina, Walter Pengue e, no Chile, Manfred Max Neef têm se projetado. No Brasil, Peter May (presidente, em 2015, da Sociedade Brasileira de Economia Ecológica, EcoEco, e ex-presidente da ISEE, em 2010-2012, além de presidente fundador da EcoEco), Maurício Amazonas, Ademar Romeiro, Luciana Togeiro, Maria Amélia Rodrigues Enríquez e Paulo Mibieli, todos ex-presidentes da EcoEco, se destacam. José Eli da Veiga, expoente das discussões sobre sustentabilidade e mudança climática, figura numa categoria que combina Georgescu, ecoeficiência e ecologismo dos pobres. Osório Viana aproxima-se da posição de Martínez Alier. Charles Mueller, que foi aluno de Georgescu-Roegen em Vanderbilt, se identifica com ele e com Herman Daly. Armando Mendes (1928-2012), grande pensador paraense, era de uma visão mais para o humanismo ecológico. Ferrenho seguidor da Georgescu é, admiravelmente, um economista do setor financeiro, Hugo Penteado, que não deixa escapar oportunidade para reforçar o significado e a importância dos ensinamentos do mestre. Sobre Georgescu, trabalho significativo é o de Andrei Cecchin (2010). O elenco de economistas ecológicos brasileiros tem se ampliado, contando com praticantes representativos do naipe de Clítia Martins, Ihering Alcoforado, Joseph Weiss, Suely Chacon, Daniel Caixeta Andrade, Valéria da Vinha, Luiz Fernando Krieger Merico.

Aceitando uma das mais bem conhecidas definições da economia, a de Robbins (1984, p. 16), que enfatiza o fato de que a economia "é a ciência que estuda o comportamento humano como uma relação entre fins e meios escassos que têm usos alternativos", considero-me firme seguidor de Georgescu-Roegen e sua visão termodinâmica do processo econômico. Central nesse entendimento é a percepção de que a natureza impõe limites incontornáveis ao funcionamento da economia. A verdadeira escassez de recursos, segundo Georgescu-Roegen, advém da Segunda Lei da Termodinâmica, que não faz parte do paradigma vigente da ciência econômica no mundo. E é, para Georgescu (1971, p. 3), a mais econômica na natureza de todas as leis naturais. Para ele, os economistas convencionais concebem um sistema econômico que é isolado, autocontido e a-histórico configurado por um fluxo circular entre produção e consumo, sem entradas e sem saídas, conforme se expõe na Figura 1. Com princípios ditados pela natureza, porém, a sociedade só pode realizar o que a natureza permitir. Crescimento econômico, assim, é algo inerentemente insustentável: não existe no mundo natural o fenômeno de crescimento contínuo; quando isso parece acontecer, o final é sempre catastrófico. Conclusão forte, mas que obriga a se pensar o desenvolvimento econômico como evolução, prosperidade, progresso - e não como o acúmulo perene, ad infinitum, de artefatos produzidos pelo sistema econômico. 


\section{Referências}

Cavalcanti, C. Concepções da Economia Ecológica: suas relações com a economia dominante e a Economia Ambiental. Estudos Avançados, 24(68), 53-67, 2010.

Cecchin, A. A natureza como limite da economia. São Paulo: Senac/Edusp, 2010.

Costanza, R. (Org.). Ecological Economics: The Science and Management of Sustainability. Nova York: Columbia University Press, 1991.

Costanza, R.; Daly, H.; Batholomew, J. Goals, agenda, and policy recommendations for ecological economics. In: Costanza, R. (Org.). Ecological Economics: The Science and Management of Sustainability. Nova York: Columbia University Press, 1991. p. 1-20.

Daly, H.; Farley, J. Ecological Economics: Principles and Applications. Washington, D.C.: Island Press, 2004.

Furtado, C. O mito do desenvolvimento econômico. Rio de Janeiro: Paz e Terra, 1974.

Gabaglia Penna, C. Conservação ambiental x crescimento econômico. Blog O Eco. 2008. Disponível em: <http://www. oeco.com.br/convidados/16819-oeco_27115>. Acesso em: 23 abr. 2008.

Georgescu-Roegen, N. The Entropy Law and the Economic Process. Cambridge, Mass., EUA: Harvard University Press, 1971.
Knight, F. Anthropology and Economics. In: Melville, J. H. Economic Anthropology: The Economic Life of Primitive Peoples. 1. ed. New York: W.W. Norton, 1940, Appendix: 508-523, 1965.

Marshall, A. Principles of Economics. [1890] 9. ed. vol. I. Londres: Macmillan, (variorum), 1961.

Martínez Alier, J. [1992] De la Economía Ecológica al Ecologismo Popular. 3. ed. Barcelona: Icaria Editorial, 1995.

Martínez Alier, J. O ecologismo dos pobres. Trad. de Maurício Waldman. São Paulo: Contexto, 2007.

McNeill, J. R. Something New Under the Sun: Un Environmental History of the Twentieth-Century World. New York: W.W. Norton, 2000.

Rezende, A. L. Os limites do possível. Rio: Companhia das Letras, 2013.

Robbins, L. B. [1932] An Essay on the Nature and Significance of Economic Science. 3. ed. London: Macmillan, 1984.

Sen, A. Development as Freedom. Oxford: Oxford University Press, 1999.

Whitehead, A. N. A função da razão. Trad. de Fernando Dídimo. Brasília: Editora da UnB, 1985. 